\title{
Solução homonímica e solução polissêmica nos Learner's Dictionaries: análise de casos e proposta de tratamento ${ }^{1}$
}

\author{
Homonimic Solution and Polysemous
}

Solution in Learner's Dictionaries:

Analysis of Cases and Treatment Proposal

Ana Flávia Souto de Oliveira*

Universidade Federal do Rio Grande do Sul (UFRGS)

Porto Alegre - Rio Grande do Sul / Brasil

RESUMO: Neste trabalho, apresentamos dois conceitos que julgamos ser fundamentais para a organização de obras lexicográficas: a solução homonímica e a solução polissêmica. Avaliamos de que forma a adoção de uma dessas soluçōes determina e influencia a apresentação da macro e da microestrutura dos dicionários. A partir do exame de verbetes extraídos aleatoriamente de quatro learner's dictionaries, percebemos que: (i) são empregadas quatro configuraçôes distintas para as soluçôes, (ii) não há uma aplicação única nas obras para o mesmo fenômeno e (iii) não há consistência entre verbetes extraídos do mesmo dicionário. Ao final, apresentamos nossa sugestão para o tratamento desses fenômenos nos learner's dictionaries, com especial atenção aos subsídios fornecidos pela Semântica Cognitiva. PALAVRAS-CHAVE: lexicografia; learner's dictionaries; solução homonímica; solução polissêmica.

ABSTRACT: In the present paper, we present two crucial concepts for the organization of lexicographic works: the homonymic solution and the polysemous solution. We evaluate in which ways the use of one of these options determines and influences dictionaries' macro and microstructures. Based on the examination of entries extracted randomly from four learner's dictionaries we found that: (i) four different design solutions are used, (ii) there was no single way to deal with the same phenomenon, and (iii) there was no consistency when comparing entries from the same dictionary. Finally, we present our suggestion for the treatment of

\footnotetext{
*anaflavia10@gmail.com

${ }^{1}$ Este trabalho traz resultados da pesquisa da autora desenvolvida durante o mestrado (bolsista CNPq), sob orientação dos professores Maity Siqueira e Félix Bugueño Miranda, e doutorado (bolsista CAPES), sob orientação da professora Maity Siqueira.
} 
these phenomena in learner's dictionaries, highlighting insights provided by Cognitive Semantics.

KEYWORDS: lexicography; learner's dictionaries; homonymic solution; polysemous solution.

\section{Introdução}

Nos dicionários, a homonímia e a polissemia podem, muitas vezes, não receber o mesmo tratamento que resultaria de uma avaliação Lexicológica desses fenômenos. Isso porque a organização dos componentes de uma obra lexicográfica deve ser realizada a partir da consideração de três fatores que determinam a constituição geral do dicionário: o perfil de usuário, a função da obra e o tipo de dicionário. Na seção 2, abordamos quais aspectos devem ser considerados ao lidar com a polissemia e a homonímia no âmbito lexicográfico.

Quanto à macroestrutura das obras, quando diferentes significados são atribuídos à mesma forma lexical, surge um problema que diz respeito à adoção do que chamamos de 'solução homonímica' ou 'solução polissêmica'. O emprego de uma dessas soluções influencia e determina a apresentação da nominata do dicionário, pois, a partir delas, é feita a escolha entre separar os itens lexicais em verbetes distintos por suas relações etimológicas, por critério morfológico ou por critério semântico - o que corresponde à solução homonímica-, ou apresentar as informaçōes relativas à forma linguística em um único verbete, independentemente, por exemplo, de qualquer relação etimológica - uma solução polissêmica. Delimitamos os quatro tipos de configuração possíveis das soluções: a adoção (i) de uma solução homonímica por critério morfológico, (ii) de uma solução homonímica por critério semântico ou etimológico, (iii) de uma solução polissêmica total e (iv) de uma solução polissêmica parcial. Essa discussão é apresentada na seção 3 do presente trabalho.

$\mathrm{Na}$ seção 4, a partir da análise de verbetes escolhidos aleatoriamente em quatro learner's dictionaries ${ }^{2}$ (CALD, 2008; COBUILD, 2006; LDCE, 2009;

\footnotetext{
${ }^{2}$ [dicionários de aprendizes] Pelo fato de o termo learner's dictionary já ser consagrado na Metalexicografia de língua inglesa para designar especificamente obras monolíngues para falantes não nativos, preferimos nos referir a esse genótipo lexicográfico mantendo a terminologia do inglês, ao invés de utilizar sua tradução. Além disso, no português, os termos dicionário de aprendizes e dicionário pedagógico abarcam diversos tipos de obras, desde os dicionários para aprendizes de língua materna até obras bilíngues voltadas ao público aprendiz.
} 
OALD, 2005), classificamos essas obras com base nos quatro tipos de solução apresentados na seção anterior, buscando delimitar qual padrão cada uma delas utiliza. Percebemos, na análise, que as obras empregam soluções bastante distintas para tratar o mesmo fenômeno e que, em alguns casos, o mesmo fenômeno é tratado de maneira diferente no mesmo dicionário.

Com base nesses resultados, na seção 5, apresentamos nossa sugestão de tratamento para esses fenômenos nos learner's dictionaries, com base em subsídios fornecidos pela Semântica Cognitiva, e buscamos demonstrar que, para a apresentação da maioria dos verbetes, o emprego de uma solução polissêmica parcial parece ser o mais apropriado.

\section{Homonímia e polissemia nos dicionários}

A homonímia ${ }^{3}$ é geralmente definida como um fenômeno no qual uma forma linguística apresenta dois ou mais significados não relacionados (RIEMER, 2010). Um exemplo de item homônimo é o inglês band, com os significados "grupo de pessoas" [bando] e "tira para unir dois ou mais elementos" [amarra]. O primeiro significado tem origem no francês antigo bande, enquanto o segundo advém do norueguês antigo band (OED, 1933, s.v. band sb. $\left.{ }^{1,2}\right){ }^{4}$

Em contraparte, os casos de polissemia ocorrem quando uma forma linguística apresenta dois ou mais significados relacionados (TAYLOR, 2003). Esse fenômeno pode ser ilustrado pelo item inglês branch, com os significados "parte menor de uma árvore" [ramo] e "uma das partes de uma organização" [filial]. Segundo OED (1933, s.v. branch), esse é um caso de polissemia, no qual os significados existentes surgiram a partir do francês antigo branche.

No que diz respeito à Lexicografia, a homonímia e a polissemia podem, muitas vezes, não receber o mesmo tratamento que resultaria de uma avaliação lexicológica desses fenômenos. Isso porque a organização dos componentes de uma obra lexicográfica deve ser sempre realizada a partir da consideração de três fatores que determinam a constituição geral do dicionário: o perfil de usuário, a função da obra e tipo de dicionário (FARIAS, 2009; OLIVEIRA, 2010).

\footnotetext{
${ }^{3}$ Não discutimos, no presente trabalho, casos de homógrafos não homófonos, pois consideramos que eles devem sempre receber um verbete distinto.

${ }^{4}$ Seguindo a tendência da metalexicografia europeia, citamos os dicionários utilizando siglas. Para localizar o verbete do qual a citação foi retirada, utilizamos a abreviatura s.v., do latim sub voce.
} 
Tradicionalmente, pensa-se que o fato de itens lexicais constituírem um caso de homonímia justificaria sua apresentação em verbetes distintos e que casos de polissemia resultariam na apresentação de apenas um verbete, com as respectivas acepções do item lexical (COWIE, 2001). Contudo, ao tratar de um item lexical polissêmico, uma obra lexicográfica pode apresentar as acepções (mesmo que relacionadas) em mais de um verbete. Inversamente, itens homonímicos podem receber apenas um verbete, desconsiderando as questôes etimológicas, semânticas ou morfológicas envolvidas.

O dicionário OBED (2006), obra para aprendizes de nível básico de inglês como língua não nativa, opta por inserir dois verbetes para o item lexical head:

head $^{1}[\ldots]$ noun 1 the part of your body above your neck [...] 4 the most important person: the Pope is the head of the Catholic Church. [...] (OBED, 2006, s.v. head ${ }^{1}$ ).

head $^{2}[\ldots]$ verb 2 to be at the front or top of a group: Michael's name heads the list. [...] (OBED, 2006, s.v. head ${ }^{2}$ ).

Os significados "lider" (substantivo) e "encabeçar/liderar" (verbo), apresentados sob os números 4 e 2, respectivamente, estão, de forma clara, relacionados semanticamente e constituem extensões figuradas do significado 1 , mais físico e concreto, "cabeça". Assim, mesmo que se trate de um caso de derivação (COWIE, 2001) com uma evidente proximidade semântica, a obra separa os significados em dois verbetes, um para cada classe gramatical. Inversamente, o dicionário OCDCE (2005), obra de tamanho reduzido para falantes nativos de inglês canadense, apresenta o seguinte verbete para o item:

head $\bullet n .1$ the part of a human's or an animal's body, containing the brain, mouth and sense organs. [...] 8 a a person in charge. $b$ a position of leadership. $\bullet v .1$ be at the head of. 2 be in charge of. [...] (OCDCE, 2005, s.v. head).

Nesse dicionário, é feita a escolha por manter os significados de head unidos em um verbete, utilizando apenas uma marcação para as diferentes classes gramaticais antes de cada grupo de definiçôes (s. e $v$.). Dessa forma, a primeira obra leva em consideração a (pouca) habilidade linguística do seu usuário e as possíveis dificuldades encontradas por ele durante a consulta, encolhendo por separar as definições do item polissêmico em duas entradas distintas. Por outro lado, o segundo dicionário opta por construir um verbete único, pois entende que, para um falante nativo, a presença de diferentes classes 
gramaticas para a mesma forma não é um fator que traga dificuldades para o usuário localizar a informação desejada.

O dicionário HOU (2001), obra monolíngue com propósitos históricos para falantes nativos de português, utiliza-se de um critério etimológico para a inserção das entradas (pois apresenta um verbete para cada conjunto de acepçôes com diferentes origens), como o caso do item lexical boleto, para qual o dicionário traz três verbetes:

${ }^{1}$ boleto /ê/ s.m. [...] MIC 1 m.q. COGUMELO (HOU, 2001, s.v. 'boleto)

${ }^{2}$ boleto /ê/ s.m. [...] 5 COM $B$ impresso, expedido por firma, instituição financeira etc. de registro de dívida e a efetuação de seu pagamento em data determinada; lâmina de pagamento [...] (HOU, 2001, s.v. ${ }^{2}$ boleto)

${ }^{3}$ boleto /ê/ s.m. 1 FER parte superior do trilho, sobre a qual se deslocam as rodas da locomotiva e dos vagões 2 HIP articulação volumosa e arredondada da perna dos cavalos [...] (HOU, 2001, s.v. ${ }^{3}$ boleto)

Os itens advêm, respectivamente, do grego bōtetese, ${ }^{1}$ boleto ("fungo"), do espanhol boleta, ${ }^{2}$ boleto ("papel”) e do francês boulet, ${ }^{3}$ boleto ("parte do trilho" e "parte de equino"). No terceiro verbete, fica evidente a adoção do critério etimológico, visto que as acepções não mantém qualquer relação semântica entre si. Tendo em vista que esse dicionário busca descrever a língua portuguesa de uma forma exaustiva e histórica, desde a primeira aparição de item lexical até as acepções de uso mais contemporâneo, a organização adotada pela obra condiz com seus propósitos, qual seja, mostrar a evolução dos significados a partir das relaçôes etimológicas entre eles.

Fica claro, assim, que independentemente de estarmos tratando de casos de homonímia ou polissemia do ponto de vista lexicológico, esses dados podem ser adaptados em uma obra lexicográfica, para melhor se adequar aos propósitos e ao público-alvo do dicionário. Na próxima seção, aprofundaremos essa discussão no âmbito lexicográfico.

\section{Solução polissêmica e solução homonímica}

Quando diferentes significados são atribuídos à mesma forma lexical, surge, assim, um problema que diz respeito à adoção do que chamamos de 'solução homonímica' ou 'solução polissêmica' (OLIVEIRA, 2010). Nos 
exemplos discutidos acima, temos, no primeiro dicionário (o OBED, 2006), uma solução homonímica, pois a obra separa os significados em entradas distintas, dependendo da classe gramatical a que esses significados pertencem. Da mesma forma, o HOU (2001) adota uma solução homonímica, contudo, o critério utilizado nessa obra é a etimologia. Já no caso do OCDCE (2005) é feita a escolha por apresentar todas as definições em um único bloco, exemplificando um caso de solução polissêmica.

Dessa forma, o emprego de uma dessas soluções influencia e determina a apresentação da nominata do dicionário, pois a partir delas é que se dá a divisão dos verbetes da obra e tem-se o número de palavras-entrada.

A solução homonímica é definida como a escolha em separar os itens lexicais em verbetes distintos, por suas relações etimológicas, por critério morfológico ou por critério semântico (OLIVEIRA, BUGUENO, SIQUEIRA, 2013). Considere o exemplo abaixo:

${ }^{1}$ banda s.f. [...] 3 faixa ou listra larga [...] (HOU, 2001, s.v. ${ }^{1}$ banda).

${ }^{2}$ banda s.f. [...] 1 grupo de seres ou de coisas; bando [...] 3 MÚS conjunto de música popular urbana [...] (HOU, 2001, s.v. ${ }^{2}$ banda).

No HOU (2001), como destacado acima, é utilizado como critério a etimologia do item lexical. No presente exemplo, temos duas entradas para banda, referentes às distintas origens geradoras dos significados. Nesse caso, temos a adoção de uma solução homonímica por critério etimológico. Porém, mesmo que esse caso seja de fácil delimitação, pois o dicionário afirma claramente seus propósitos histórico-etimológicos, cabe salientar que a distinção entre uma solução homonímica por critério etimológico e uma por critério semântico, algumas vezes, não se dá de forma clara. Entendemos que, mesmo que às vezes o resultado da estruturação a partir desses dois critérios coincida, eles não são iguais. Contudo, pelo fato de alguns dicionários não explicitarem o critério empregado para tal organização, muitas vezes não é possível asseverar qual dos critérios está sendo utilizado para a organização das entradas. Por isso, preferimos manter esses dois tipos em uma única categoria, a solução homonímica por critério etimológico ou semântico.

O segundo tipo de solução homonímica é a por critério morfológico. Neste tipo, é trazido um verbete para cada classe gramatical do item. Por exemplo, o caso do OBED (2006): 
bank $^{1}[\ldots]$ noun 1 a place that keeps money safe for people [...] 2 the land along the side of a river [...] (OBED, 2006, s.v. bank $\left.{ }^{1}\right)$.

bank $^{2}[\ldots]$ verb $[\ldots]$ to keep your money in a particular bank (OBED, 2006, s.v. bank ${ }^{2}$.

No exemplo acima, é desconsiderado o fato de que os dois significados do substantivo bank contidos no primeiro verbete são, na verdade, homônimos e apresentados sob uma única entrada. Contudo, para a forma verbal, é trazido um verbete distinto (mesmo que seu significado seja semanticamente relacionado à primeira acepção da outra entrada). Sendo assim, esse exemplo caracteriza a adoção de uma solução homonímica por critério morfológico, no qual cada classe gramatical constitui uma palavraentrada específica e, consequentemente, apresentada em outro verbete.

A solução polissêmica, por sua vez, caracteriza casos nos quais as informações relativas à forma linguística estão dispostas em um único verbete, independentemente de qualquer relação etimológica, morfológica ou semântica (OLIVEIRA; BUGUEÑO; SIQUEIRA, 2013). Para esse tipo, encontramos duas organizações: a solução polissêmica total e a solução polissêmica parcial.

$\mathrm{Na}$ solução polissêmica total, todas as acepções do item em questão são apresentadas em um verbete único, sem que haja qualquer divisão explícita no verbete quanto à classe gramatical e a relações semânticas e etimológicas, ou seja, as acepções são trazidas em um bloco único de texto corrido. Considere o verbete abaixo:

expatriate adj [...] 1 resident outside one's native country 2 exiled or banished from one's native country $>n[\ldots] 3$ a person living outside his native country 4 an exile; expatriate person $>v b[\ldots] 5$ to exile (oneself) from one's native country or cause (another) to go into exile [...] (CEDCE, 2005, s.v. expatriate).

Nesse verbete, as acepções do item expatriate são apresentadas em um único verbete, de forma sequencial, sem que haja uma divisão interna em blocos pelas classes gramaticais: mesmo que haja uma pequena divisão sequencial dos significados apresentados, quanto às formas adjetivas, substantivas e verbais, o verbete tem uma estrutura linear.

Já no emprego de uma solução polissêmica parcial, mesmo que haja apenas uma palavra-entrada, sob a qual todas acepções estão subsumidas, existe uma divisão interna desse verbete, explicitamente separando as diferentes classes gramaticais ou os diferentes blocos de significado. Veja o seguinte verbete: 
low $[\ldots]$

- adj. [...]

- NOT HIGH/TALL 1 not high or tall; not far above the ground [...]

- NEAR THE BOTTOM 2 at or near the bottom of sth [...]

- LEVEL/VALUE 4 [...] bellow the usual or average amount, level or value $[\ldots] 5$ having a reduced amount or not enough of sth $[\ldots]$

- $a d v$. [...]

- NOT HIGH 1 in or into a low position, not far above the ground [...]

- noun

- LEVEL/VALUE 1 a low level or point; a low figure [...]

- DIFFICULT TIME 2 a very difficult time time in sb's life or carrer [...]

- verb [V] (literary) when a cow lows, it makes a deep sound [...] (OALD, 2005, s.v. low)

No exemplo acima, as acepções são apresentadas em um único verbete, porém, elas são divididas em blocos a partir das classes gramaticais as quais pertencem, subdivididas em adjetivo, advérbio, substantivo e verbo. Além disso, há também uma subdivisão semântica, no caso das acepções 4 e 5 da classe adjetiva, em comparação às de número 1 e 2 . Dessa forma, nesse verbete, encontramos os dois tipos de solução polissêmica parcial: uma por critério semântico e uma por critério morfológico.

Resumimos, no quadro abaixo, os quatro tipos de solução.

\section{QUADRO 1}

Tipos de solução e definição de cada um deles

\begin{tabular}{|l|l|}
\hline \multicolumn{1}{|c|}{ Solução } & \multicolumn{1}{|c|}{ Definição } \\
\hline $\begin{array}{l}\text { homonímica por } \\
\text { critério semântico } \\
\text { ou etimológico }\end{array}$ & $\begin{array}{l}\text { mais de um verbete para a mesma forma: os verbetes são separados pela } \\
\text { etimologia dos itens lexicais ou por diferenças semânticas; }\end{array}$ \\
\hline $\begin{array}{l}\text { homonímica por } \\
\text { critério morfológico }\end{array}$ & $\begin{array}{l}\text { mais de um verbete para a mesma forma: os verbetes são separados } \\
\text { conforme as classes gramaticais apresentadas pelo item lexical; }\end{array}$ \\
\hline polissêmica total & $\begin{array}{l}\text { um verbete para cada forma: as acepçóes são trazidas em um único } \\
\text { verbete e em um único bloco, desconsiderando suas relações } \\
\text { etimológicas, semânticas e morfológicas; }\end{array}$ \\
\hline polissêmica parcial & $\begin{array}{l}\text { um verbete para cada forma: as acepçôes são trazidas em um único } \\
\text { verbete, mas que apresenta uma divisão interna conforme as classes } \\
\text { gramaticais apresentadas pelo item, ou por critério semântico. }\end{array}$ \\
\hline
\end{tabular}

Reforçamos que essa análise pode ocorrer em dois níveis. Em primeiro lugar, quanto à diferenciação etimológica ou semântica entre homonímia e polissemia. Nesse caso, pode ser feita uma divisão do item lexical em mais de 
um verbete a partir das relações semânticas ou etimológicas mantidas entre as acepções (solução homonímica) ou pode ser adotada uma solução polissêmica, porém com uma divisão interna no verbete em blocos por critério semântico ou etimológico (solução polissêmica parcial). Em segundo lugar, quanto à apresentação das acepções das diferentes classes gramaticais dos itens. Nesse caso, pode-se escolher entre trazer um verbete para cada classe gramatical que o item lexical apresenta (solução homonímica morfológica), apresentar todas as acepções em um verbete único, sem demarcação entre as acepções de classes gramaticais distintas (solução polissêmica total), ou trazer todas as acepções em um verbete único, mas com uma divisão interna em blocos das classes gramaticais (solução polissêmica parcial). Dessa forma, nos verbetes, é possível que ocorra mais de um tipo de solução, uma referente a cada um desses níveis.

Após definirmos e apresentarmos exemplos dos tipos de solução, passamos agora à análise específica dos quatro learner's dictionaries.

\section{Análise dos learner's dictionaries}

Nesta parte do trabalho, buscamos avaliar de que forma os quatro principais learner's dictionaries (CALD, 2008; COBUILD, 2006; LDCE, 2009; OALD, 2005) organizam a apresentação das palavras-entrada. Em seus front matters, ${ }^{5}$ encontramos algumas informações que podem ser úteis para tal delimitação. Em Oliveira; Bugueño; Siqueira (2013), apresentamos essas informações, que são resumidas abaixo:

- CALD (2008, p. x): afirma que apresenta as diferentes classes gramaticais de um item lexical dentro do mesmo verbete, porém, separadas em blocos distintos, ou seja, uma solução polissêmica parcial. O dicionário não explicita se a homonímia e a polissemia são tratadas de modo distinto.

- COBUILD (2006, p. ix): afirma que apresenta diferentes entradas para itens com "clear sense splits" [divisôes claras de significado], ou seja, uma solução homonímica por critério semântico, porém, não especifica em quais casos essa divisão é empregada, ou quais critérios

\footnotetext{
${ }^{5} \mathrm{O}$ front matter é um dos possíveis componentes do outside matter dos dicionários, junto com o middle matter e o back matter. Segundo Hausmann e Wiegand (1989, p. 330-331), o front matter corresponde às partes funcionais que precedem a nominata, como guia de uso e quadro de abreviaturas.
} 
são utilizados, nem se existe diferença no tratamento de itens homonímicos e polissêmicos. ${ }^{6}$

- LDCE (2009, p. x): separa itens lexicais com diferentes classes gramaticais em verbetes distintos (uma solução homonímica morfológica), porém, também não faz referência à diferenciação entre homonímia e polissemia.

- OALD (2005, p. ix): afirma que itens lexicais que apresentam diferentes classes gramaticais são estruturados em verbete único, mas organizados em blocos distintos (uma solução polissêmica parcial). Já os casos de homônimos não-homófonos ${ }^{7}$ são apresentados em entradas distintas. Nenhum comentário é feito a respeito da distinção entre polissemia e homonímia.

No quadro abaixo, sintetizamos essas colocaçôes:

\section{QUADRO 2}

Informações contidas no front matter de CALD (2008), COBUILD (2006), LDCE (2009) e OALD (2005) que têm relação com o emprego da solução homonímica e de solução polissêmica

\begin{tabular}{|l|l|l|l|l|}
\hline & CALD (2008) & COBUILD (2006) & LDCE (2009) & OALD (2005) \\
\hline $\begin{array}{l}\text { Diferenciação } \\
\text { entre } \\
\text { homonímia e } \\
\text { polissemia }\end{array}$ & não explicitada; & não explicitada; & não explicitada; & $\begin{array}{l}\text { não explicitada; } \\
\text { homônimos não- } \\
\text { homófonos em } \\
\text { verbetes distintos; }\end{array}$ \\
\hline $\begin{array}{l}\text { Classes } \\
\text { gramaticais }\end{array}$ & $\begin{array}{l}\text { verbete único, em } \\
\text { blocos diferentes } \\
\text { por classe } \\
\text { gramatical; }\end{array}$ & não explicitada; & $\begin{array}{l}\text { verbetes distintos } \\
\text { para cada classe } \\
\text { gramatical }\end{array}$ & $\begin{array}{l}\text { verbete único, } \\
\text { em blocos diferentes } \\
\text { por classe gramatical. }\end{array}$ \\
\hline $\begin{array}{l}\text { Outros } \\
\text { comentários }\end{array}$ & $-\begin{array}{l}\text { diferentes } \\
\text { verbetes para } \\
\text { "divisões claras } \\
\text { de significado" }\end{array}$ & $-\begin{array}{l}\text { soção homonímica } \\
\text { por critério } \\
\text { semântico }\end{array}$ & $\begin{array}{l}\text { solução } \\
\text { polissêmica } \\
\text { parcial }\end{array}$ & $\begin{array}{l}\text { solução homonímica } \\
\text { morfológica }\end{array}$ \\
\hline $\begin{array}{l}\text { Tipo de } \\
\text { solução } \\
\text { empregada }\end{array}$ & $\begin{array}{l}\text { solução } \\
\text { polissêmica } \\
\text { parcial }\end{array}$ & \multicolumn{3}{|l}{} \\
\hline
\end{tabular}

Fonte: Adaptado de Oliveira, 2010

${ }^{6}$ Pelo fato da distinção entre homonímia e polissemia nem sempre ser clara, considerar diferenças de significado como critério de separação de verbetes não garante que a polissemia e a homonímia sejam evidenciadas. Além disso, considerar como critério as "divisões claras de significado" torna necessário que sejam feitas afirmaçóes mais aprofundada a respeito da metodologia empregada para tal.

${ }^{7}$ Ver nota 3. 
A partir da análise de verbetes retirados dessas obras, classificamos os dicionários com base nos quatro tipos de solução apresentados na seção anterior e nas informações trazidas pelas próprias obras, buscando: (i) delimitar qual solução cada uma das obras adota para cada de fenômeno, (ii) perceber se o mesmo dicionário mantém um padrão no tratamento do mesmo tipo de fenômeno e (iii) avaliar se há homogeneidade no emprego das soluções entre as obras para casos semelhantes.

Os itens lexicais selecionados foram: bank, case, exile, head, long, pop, rocket, roll, sack e vest. Para a seleção dos verbetes, utilizamos os seguintes critérios: verbetes de itens lexicais homônimos, verbetes de itens polissêmicos, itens lexicais utilizados em mais de uma classe gramatical com a mesma forma e verbetes que apresentavam mais de uma acepção.

No Apêndice 1, apresentamos as análises integrais relativas aos verbetes desses itens lexicais e ao tipo de solução utilizada em cada um dos quatro dicionários. No Quadro 3, trazemos as tendências gerais de adoção das soluçôes que encontramos em cada uma das obras.

\section{QUADRO 3}

Análise da tendência da solução adotada por cada dicionário

\begin{tabular}{|l|l|l|l|l|}
\hline & CALD (2008) & COBUILD (2006) & LDCE (2009) & OALD (2005) \\
\hline $\begin{array}{l}\text { Casos de } \\
\text { homonímia } \\
\text { (quantidade } \\
\text { de verbetes) }\end{array}$ & $\begin{array}{l}\text { Solução } \\
\text { polissêmica }\end{array}$ & $\begin{array}{l}\text { Solução } \\
\text { homonímica } \\
\text { etimológica } \\
\text { ou semântica }\end{array}$ & $\begin{array}{l}\text { Solução } \\
\text { polissêmica }\end{array}$ & $\begin{array}{l}\text { Solução } \\
\text { polissêmica }\end{array}$ \\
\hline $\begin{array}{l}\text { Diferentes } \\
\text { classes } \\
\text { gramaticais }\end{array}$ & $\begin{array}{l}\text { Solução } \\
\text { polissêmica } \\
\text { parcial }\end{array}$ & $\begin{array}{l}\text { Solução } \\
\text { polissêmica } \\
\text { total }\end{array}$ & $\begin{array}{l}\text { Solução } \\
\text { homonímica } \\
\text { morfológica }\end{array}$ & $\begin{array}{l}\text { Solução } \\
\text { polissêmica parcial }\end{array}$ \\
\hline Descrição & $\begin{array}{l}\text { não diferencia } \\
\text { casos de } \\
\text { polissemia e } \\
\text { homonímia e } \\
\text { traz um verbete } \\
\text { com blocos de } \\
\text { classes gramaticais }\end{array}$ & $\begin{array}{l}\text { um verbete para } \\
\text { cada núcleo de } \\
\text { significado, } \\
\text { intercalando } \\
\text { acepções de } \\
\text { diferentes classes } \\
\text { gramaticais }\end{array}$ & $\begin{array}{l}\text { não diferencia } \\
\text { casos de polissemia } \\
\text { e homonímia e } \\
\text { traz um verbete } \\
\text { para cada classe } \\
\text { gramatical }\end{array}$ & $\begin{array}{l}\text { não diferencia } \\
\text { casos de pomonímia e } \\
\text { traz um verbete } \\
\text { com blocos de } \\
\text { classes gramaticais }\end{array}$ \\
\hline
\end{tabular}

Notamos que há uma tendênciageral das obras de desconsiderar a diferenciação entre homonímia e polissemia, ou seja, a maioria adota uma solução polissêmica, incluindo no mesmo verbete acepçóes com diferentes origens etimológicas e/ou que não estão semanticamente relacionadas (dos quatro dicionários, apenas um divide os verbetes por critério etimológico/semântico). Contudo, percebemos, também, que 
as obras empregam soluçōes bastante distintas para tratar das diferentes classes gramaticais que a forma lexical pode assumir. Por exemplo, a esse respeito, encontramos três tipos de organização: solução polissêmica parcial (ou seja, um verbete dividido em blocos, um para cada classe gramatical), solução polissêmica total (um verbete intercalando acepçóes de diferentes classes gramaticais) e solução homonímica morfológica (um verbete diferente para cada classe gramatical). No Quadro 4, apresentamos exemplos extraídos de cada uma das obras.

\section{QUADRO 4}

Exemplos de tratamento das diferentes classes gramaticais

\begin{tabular}{|c|c|c|}
\hline Solução empregada & Obras que a utilizam & Exemplo de verbete \\
\hline $\begin{array}{l}\text { Solução polissêmica } \\
\text { parcial }\end{array}$ & $\begin{array}{l}\text { CALD, } 2008 \\
\text { OALD, } 2005\end{array}$ & $\begin{array}{l}\text { bank } \\
\text { noun }[\mathrm{C}] \text { MONEY } 1 \text { an organization where } \\
\text { people and businesses can invest or borrow } \\
\text { Money, change it to a foreign Money, etc., or a } \\
\text { building where these services are offered [...] } \\
\text { verb MONEY } 1 \text { [I or T] to keep your money } \\
\text { in total a particular bank, or to put money into a } \\
\text { bank (CALD, 2008) }\end{array}$ \\
\hline Solução polissêmica & COBUILD, 2006 & $\begin{array}{l}\text { (1) bank [...] } 1 \text { A bank is an institution where } \\
\text { people or businesses can keep their money. [...] } \\
3 \text { If you bank money, you pay it into a bank. [...] }\end{array}$ \\
\hline $\begin{array}{l}\text { Solução homonímica } \\
\text { morfológica }\end{array}$ & LDCE, 2009 & $\begin{array}{l}\text { bank }^{1}[\ldots] n \\
1 \text { PLACE FOR MONEY a) a business that } \\
\text { keeps and lends money and provides other } \\
\text { financial services }[\ldots] \\
\text { bank }^{2} v \\
1 \text { MONEY a) }[\mathrm{T}] \text { to put or keep money in a } \\
\text { bank }[\ldots]\end{array}$ \\
\hline
\end{tabular}

Além disso, em alguns casos, o mesmo fenômeno é tratado de maneira diferente no mesmo dicionário. Por exemplo, o COBUILD (2006) normalmente utiliza a solução homonímica etimológica para a estruturação dos verbetes, como em bank e case. Porém, em verbetes pequenos, a obra opta por uma solução polissêmica total, como ocorre nos verbetes de rocket e pop, fato esse que torna a apresentação das acepções muito estranha se considerarmos que a obra diz se preocupar com a questão semântica para a estruturação dos verbetes.

Finalmente, percebemos que em nenhuma das obras há a preocupação por manter próximas as acepções semanticamente relacionadas (com algumas poucas exceções - não sistemáticas - destacadas no Apêndice 1), seja através de blocos semânticos (com uma solução polissêmica parcial), seja pelo uso de recursos gráficos que explicitariam uma hierarquia semântica entre as acepçóes. 
Por exemplo, para o item sack, OALD (2005) traz o seguinte verbete: sack

- noun $1[\mathrm{C}]$ a large bag with no handles, made of strong rough material or strong paper or plastic, used for storing and carrying, for example flour, coal, etc. [...] 3 the contents of a sack [...] 6 [...] the act of stealing and destroy property in a captured town [...] (OALD, 2005 , s.v. sack)

As acepções 1 e 3 contidas no verbete estão em uma clara relação metonímica, fato esse que é ignorado pela obra na representação gráfica do verbete e, desse modo, não diferenciado das outras acepções que não mantém qualquer relação semântica, como a contida na acepção de número 6, "saque".

O recurso que a maior parte das obras utiliza são as chamadas guidewords. Elas são palavras-guia que, como o próprio nome sugere, auxiliam o consulente na busca pela acepção pretendida, fornecendo uma breve paráfrase de tal acepção (geralmente sinonímica) ou uma informação pragmática. Nota-se, contudo, que as guidewords podem desempenhar outra função fundamental na estruturação do verbete, qual seja, agrupar acepções que compartilham conteúdo semântico.

\section{Proposta para o emprego da solução em learner's dictionaries}

Com base nesses resultados, passamos agora a apresentar nossa sugestão de tratamento para esses fenômenos nos learner's dictionaries.

Uma das principais contribuições da Linguística Cognitiva para a análise lexical é o renovado interesse dado ao estudo da estrutura das categorias lexicais e da polissemia. Essa abordagem busca incorporar a flexibilidade e a instabilidade do significado em seus modelos de descrição da estrutura semântica (GEERAERTS, 2010). Nessa linha, segundo Tuggy (2006), tais consideraçōes levam a uma concepção na qual as próprias noçōes de demarcação lexical não podem ser tidas como absolutas, e que esses fenômenos fazem parte de um continuum homonímia-polissemia-vagueza, que compreende desde casos mais prototípicos de homonímia até casos mais explícitos e prontamente identificáveis de polissemia. Entre esses polos, haveria instâncias intermediárias, o que explicaria a dificuldade sincrônica de diferenciar alguns casos de homonímia e polissemia.

Ao transpor tais consideraçōes para a organização dos verbetes dos learner's dictionaries, entendemos que essa distinção prática entre homonímia e polissemia não é relevante para o usuário da obra, nem se encaixa no que é 
esperado desse tipo de dicionário. O que parece ser mais pertinente é o aspecto semântico, do compartilhamento ou não de significado entre as acepções.

Assim, propomos que, para a maioria dos verbetes, o mais adequado é a adoção de uma solução polissêmica parcial, pois (i) tal organização poupa espaço físico nas obras, o que está de acordo com as demandas editoriais; (ii) pelo conhecimento linguístico do usuário no nível avançado, espera-se que ele saiba a classe gramatical que procura, o que torna uma solução homonímica morfológica desnecessária; (iii) parece-nos que tal estruturação é visualmente mais atraente e de fácil utilização para o usuário.

Desse modo, propomos que os learner's dictionaries devem empregar uma solução polissêmica parcial, ou seja, apresentar um verbete para cada forma, mas com divisão interna em blocos para as diferentes classes gramaticais, como já é feito pelo CALD (2008) e pelo OALD (2005). Na figura abaixo, demonstramos como seria tal organização para o item lexical low:

$$
\begin{aligned}
& \text { low } \\
& \text { - adj. } \\
& \text { - adv. } \\
& \text { - noun } \\
& \text { - verb }
\end{aligned}
$$

FIGURA 1 - Blocos de classes gramaticais para o verbete de low

Contudo, a diferença principal da nossa proposta é inserir uma solução polissêmica parcial por critério semântico ou etimológico em cada um desses blocos de classes gramaticais, de forma que as acepções sejam apresentadas a partir das relaçōes de significado existentes entre elas. Por exemplo, o caso de band:

band n. [C]

I GROUP OF PEOPLE: 1 a group of people that get together for a particular reason 1.1 a group of musicians that play a particular kind of music together

II STRIP

MATERIAL 2 a narrow piece of sth that is put around things to hold them together 2.1 a ring 2.2 a piece of cloth which forms part of a piece of clothing

RANGE 2.a a range of values to measure sth $2 . \mathbf{b}$ a range of radio waves

CONTRAST 3 a strip of sth that contrasts with what is around

FIGURA 2 - Detalhe da solução polissêmica parcial por critério semântico, com o uso de guidewords (em destaque) 
Dentro de cada bloco morfológico, haveria uma solução homonímica semântica ou etimológica. Assim, as acepções seriam agrupadas em torno de núcleos semânticos (no exemplo acima, representado pelos algarismos romanos I e II), explicitados através da utilização de guidewords.

\section{Considerações finais}

No presente artigo, avaliamos de que forma quatro learner's dictionaries apresentam seus verbetes com relação à adoção de uma solução homonímica ou polissêmica. A partir dos verbetes analisados, constatamos que o mesmo fenômeno lexical pode receber diferentes tratamentos em cada uma das obras e que verbetes extraídos do mesmo dicionário mostram que, em alguns casos, não há consistência na forma de apresentação dos verbetes. Tais fatos ilustram a importância do estudo das soluções adotadas pelas obras e demonstram certa falta de um entendimento comum de como elas devem ser empregadas em dicionários monolíngues para aprendizes de inglês como L2.

Nossa proposta para o emprego da solução em learner's dictionaries parte do reconhecimento da flexibilidade e instabilidade do significado, o que torna as próprias noções de homonímia e polissemia não absolutas. A sugestão de verbete apresentada, contudo, possui suas restriçôes, pois compreende apenas uma classe gramatical. No caso de itens lexicais bastante polissêmicos que apresentam acepções de mais de uma classe gramatical, seria, por exemplo, necessário optar por manter significados semanticamente relacionados próximos ou por separá-los por serem de diferentes classes gramaticais.

Finalmente, seria fundamental para a validação das propostas que fossem realizados experimentos sobre a influência dessa organização no uso dos dicionários, tanto para o tempo de consulta quanto para a escolha da acepção correta.

\section{Referências}

COWIE, A. P. Homonymy, polysemy and the monolingual English dictionary. Lexicographica, v.17, p. 40-60, 2001.

FARIAS, V. S. Desenho de um dicionário escolar de língua portuguesa. 2009. $285 f$. Dissertação (Mestrado em Letras) - Instituto de Letras, Universidade Federal do Rio Grande do Sul, Porto Alegre, 2009.

GEERAERTS, D. Theories of Lexical Semantics. Oxford/New York: Oxford University Press, 2010. 
HAUSMANN, F. J.; WIEGAND, H. E. Theory of Monolingual Lexicography I: Components and Structures of Dictionaries. In: HAUSMANN, F. J., REICHMANN, O.; WIEGAND, H. E.; ZGUSTA, L. (Hrsgn.). Wörterbucher, Dictionaries, Dictionnaires: ein internationales Handbuch zur Lexikographie. Berlin: Walter de Gruyter, 1989.

OLIVEIRA, A. F. S. Subsídios da Semântica Cognitiva para a disposição das acepçôes nos learner's dictionaries. 2010. 231f. Dissertação (Mestrado em Letras) - Instituto de Letras, Universidade Federal do Rio Grande do Sul, Porto Alegre, 2010.

OLIVEIRA, A. F. S.; BUGUEÑO, F. V.; SIQUEIRA, M. O tratamento da polissemia e da homonímia nos learner's dictionaries: subsídios da semântica cognitiva para a disposição das acepções. Alfa: Revista de Linguística, 2013. [no prelo]

RIEMER, N. Introducing Semantics. Cambridge: CUP, 2010.

TAYLOR, J. Linguistic Categorization. Oxford/New York: Oxford University Press, 2003.

TUGGY, David. Ambiguity, polysemy and vagueness. In: GEERAERTS, D. (Org.). Cognitive Linguistics: Basic Readings. Berlin/New York: Mouton de Gruyter, 2006.

\section{Referências lexicográficas}

CALD. Cambridge Advanced Learner's Dictionary. Cambridge: Cambridge University Press, 2008.

COBUILD. Collins COBUILD Advanced Learner's Dictionary. Glasgow: Harper Collins Publishers, 2006.

HOU. HOUAISS, A. Dicionário Houaiss da língua portuguesa. Rio de Janeiro: Objetiva, 2001.

LDCE. Longman Dictionary of Contemporary English. Essex: Pearson Education Limited, 2009.

OALD. Oxford Advanced Learner's Dictionary. Oxford: OUP, 2005.

OALD. Oxford Advanced Learner's Dictionary. Oxford: OUP, 2010.

OBED. Oxford Basic English Dictionary. Oxford: OUP, 2006.

OCDCE. BARBER, K. et al. Oxford Canadian Dictionary of Current English. Oxford: OUP, 2005.

OED. The Oxford English Dictionary. Oxford: Clarendon Press, 1933. 


\section{Apêndice 1}

\section{Análise dos itens lexicais selecionados nos quatro dicionários}

\begin{tabular}{|c|c|c|c|c|}
\hline \multirow{2}{*}{\begin{tabular}{|l|} 
Item \\
lexical \\
\end{tabular}} & \multicolumn{4}{|c|}{ Solução adotada nos dicionários } \\
\hline & CALD (2008) & COBUILD (2006) & LDCE (2009) & OALD (2005) \\
\hline bank & $\begin{array}{l}\text { - um verbete: } \\
\text { solução polissêmica; } \\
\text { - blocos por classe } \\
\text { gramatical: parcial; } \\
\text { - usa guidewords, mas } \\
\text { num bloco único. }\end{array}$ & $\begin{array}{l}\text { - três verbetes: } \\
\text { solução homonímica; } \\
\text { - por significados: } \\
\text { etimológica ou } \\
\text { semântica; } \\
\text { - sem divisão entre } \\
\text { as classes gramaticais: } \\
\text { total; } \\
\text { - sem guidewords. }\end{array}$ & $\begin{array}{l}\text { - dois verbetes: } \\
\text { solução homonímica; } \\
\text { - um para cada classe } \\
\text { gramatical: morfológica; } \\
\text { - usa guidewords; } \\
\text { - não relaciona } \\
\text { significados } \\
\text { semanticamente } \\
\text { próximos, } \\
\text { exceto uma extensão } \\
\text { metonímica. } \\
\end{array}$ & $\begin{array}{l}\text { - um verbete: } \\
\text { solução polissêmica; } \\
\text { - blocos por classe } \\
\text { gramatical: parcial; } \\
\text { - usa guidewords; } \\
\text { - não relaciona } \\
\text { significados } \\
\text { semanticamente } \\
\text { próximos. }\end{array}$ \\
\hline case & $\begin{array}{l}\text { - um verbete: } \\
\text { solução polissêmica; } \\
\text { - usa guidewords, } \\
\text { cada significado } \\
\text { recebe um bloco; } \\
\text { - não relaciona blocos } \\
\text { semanticamente } \\
\text { próximos, apenas } \\
\text { alguns significados. }\end{array}$ & $\begin{array}{l}\text { - três verbetes: } \\
\text { soluçáo homonímica; } \\
\text { com menu por } \\
\text { significado: } \\
\text { etimológica ou } \\
\text { semântica; } \\
\text { - sem guidewords; } \\
\text { - não relaciona signi- } \\
\text { ficados semanticamente } \\
\text { próximos; } \\
\text { Só N. }\end{array}$ & $\begin{array}{l}\text { - dois verbetes: } \\
\text { soluçáo homonímica; } \\
\text { - um para cada classe } \\
\text { gramatical: morfológica } \\
\text { - usa guidewords; } \\
\text { - não relaciona blocos } \\
\text { de significado } \\
\text { semanticamente } \\
\text { próximos. }\end{array}$ & $\begin{array}{l}\text { - um verbete: } \\
\text { solução polissêmica; } \\
\text { - blocos por classe } \\
\text { gramatical: parcial; } \\
\text { - usa guidewords; } \\
\text { - não relaciona } \\
\text { significados } \\
\text { semanticamente } \\
\text { próximos. }\end{array}$ \\
\hline exile & $\begin{array}{l}\text { - um verbete: } \\
\text { soluçáo polissêmica; } \\
\text { - blocos por classe } \\
\text { gramatical: parcial; }\end{array}$ & $\begin{array}{l}\text { - um verbete: } \\
\text { solução polissêmica; } \\
\text { - não separa classes } \\
\text { gramaticais: total } \\
\text { (intercala acepçōes } \\
\text { de N e V); } \\
\text { - não relaciona acepções } \\
\text { semanticamente } \\
\text { próximas. }\end{array}$ & $\begin{array}{l}\text { - dois verbetes: } \\
\text { solução homonímica; } \\
\text { - um para cada classe } \\
\text { gramatical: morfológica; }\end{array}$ & $\begin{array}{l}\text { - um verbete: } \\
\text { solução polissêmica; } \\
\text { - blocos por classe } \\
\text { gramatical: parcial; } \\
\text { - sem guidewords; }\end{array}$ \\
\hline head & $\begin{array}{l}\text { - um verbete: } \\
\text { solução polissêmica; } \\
\text { - blocos por classe } \\
\text { gramatical: parcial; } \\
\text { - guidewords para os } \\
\text { significados, cada um } \\
\text { recebe um bloco; } \\
\text { - não relaciona blocos } \\
\text { semanticamente } \\
\text { próximos, apenas } \\
\text { alguns significados. }\end{array}$ & $\begin{array}{l}\text { - um verbete: } \\
\text { solução polissêmica; } \\
\text { - não separa classes } \\
\text { gramaticais: total; } \\
\text {-intercala acepçōes } \\
\text { de N e V; } \\
\text { - não relaciona acepções } \\
\text { semanticamente } \\
\text { próximas. }\end{array}$ & $\begin{array}{l}\text { - dois verbetes: } \\
\text { soluçáo homonímica; } \\
\text { - um para cada classe } \\
\text { gramatical: morfológica; } \\
\text { - não relaciona blocos } \\
\text { de significado } \\
\text { semanticamente } \\
\text { próximos. } \\
\text { - traz acepçōes } \\
\text { metonímicas para } \\
\text { diferentes coisas } \\
\text { separadas. }\end{array}$ & $\begin{array}{l}\text { - um verbete: } \\
\text { solução polissêmica; } \\
\text { - blocos por classe } \\
\text { gramatical: parcial; } \\
\text { - usa guidewords; } \\
\text { - não relaciona } \\
\text { significados } \\
\text { semanticamente } \\
\text { próximos. }\end{array}$ \\
\hline
\end{tabular}




\begin{tabular}{|c|c|c|c|c|}
\hline long & $\begin{array}{l}\text { - um verbete: } \\
\text { solução polissêmica; } \\
\text { - blocos por classe } \\
\text { gramatical: parcial; } \\
\text { - guidewords, mas } \\
\text { num bloco único. }\end{array}$ & $\begin{array}{l}\text { - quatro verbetes com } \\
\text { menu: solução } \\
\text { homonímica } \\
\text { etimológica ou } \\
\text { semântica (um é } \\
\text { para expressões } \\
\text { sintagmáticas = } \\
\text { não conta); } \\
\text { - sem guidewords; } \\
\text { - não relaciona } \\
\text { significados } \\
\text { semanticamente } \\
\text { próximos (mesmo } \\
\text { que alguns acabem } \\
\text { estando em sequência). }\end{array}$ & $\begin{array}{l}\text { - três verbetes: } \\
\text { solução homonímica; } \\
\text { - um para cada classe } \\
\text { gramatical: morfológica; } \\
\text { - guidewords para o } 1^{\circ} ; \\
\text { - não relaciona } \\
\text { significados } \\
\text { semanticamente } \\
\text { próximos. }\end{array}$ & $\begin{array}{l}\text { - um verbete: } \\
\text { solução polissêmica; } \\
\text { - blocos por classe } \\
\text { gramatical: parcial; } \\
\text { - usa guidewords; } \\
\text { - une acepções } \\
\text { próximas, mas } \\
\text { poderia usar uma } \\
\text { mais geral. }\end{array}$ \\
\hline pop & $\begin{array}{l}\text { - um verbete: } \\
\text { solução polissêmica; } \\
\text { - blocos por classe } \\
\text { gramatical: parcial; } \\
\text { - guidewords, mas } \\
\text { num bloco único. }\end{array}$ & $\begin{array}{l}\text { - um verbete: } \\
\text { solução polissêmica; } \\
\text { - não separa classes } \\
\text { gramaticais: total; } \\
\text {-intercala acepções } \\
\text { de N e V; } \\
\text { - sem guidewords; } \\
\text { - não relaciona acepções } \\
\text { semanticamente } \\
\text { próximas. }\end{array}$ & $\begin{array}{l}\text { - dois verbetes: } \\
\text { solução homonímica; } \\
\text { - um para cada classe } \\
\text { gramatical: morfológica; } \\
\text { - usa guidewords; } \\
\text { - não relaciona } \\
\text { significados } \\
\text { semanticamente } \\
\text { próximos; }\end{array}$ & $\begin{array}{l}\text { - um verbete: } \\
\text { solução polissêmica; } \\
\text { - blocos por classe } \\
\text { gramatical: parcial; } \\
\text { - usa guidewords; } \\
\text { - não relaciona } \\
\text { significados } \\
\text { semanticamente } \\
\text { próximos. }\end{array}$ \\
\hline rocket & $\begin{array}{l}\text { - um verbete: } \\
\text { solução polissêmica; } \\
\text { - blocos por classe } \\
\text { gramatical: parcial; } \\
\text { - guidewords, mas em } \\
\text { bloco único. }\end{array}$ & $\begin{array}{l}\text { - um verbete: } \\
\text { solução polissêmica; } \\
\text { - não separa classes } \\
\text { gramaticais: total; } \\
\text {-intercala acepções } \\
\text { de N e V; } \\
\text { - sem guidewords; } \\
\text { - não relaciona acepções } \\
\text { semanticamente } \\
\text { próximas. } \\
\end{array}$ & $\begin{array}{l}\text { - dois verbetes: } \\
\text { solução homonímica; } \\
\text { - um para cada classe } \\
\text { gramatical: morfológica; } \\
\text { - sem guidewords; } \\
\text { - não relaciona } \\
\text { significados } \\
\text { semanticamente } \\
\text { próximos; }\end{array}$ & $\begin{array}{l}\text { - um verbete: } \\
\text { solução polissêmica; } \\
\text { - blocos por classe } \\
\text { gramatical: parcial; } \\
\text { - sem guidewords; } \\
\text { - não relaciona } \\
\text { significados } \\
\text { semanticamente } \\
\text { próximos. }\end{array}$ \\
\hline roll & $\begin{array}{l}\text { - um verbete: } \\
\text { solução polissêmica; } \\
\text { - blocos por classe } \\
\text { gramatical: parcial; } \\
\text { - guidewords por blocos } \\
\text { de significado - v: } \\
\text { blocos separados; } \\
\text { n: bloco único; } \\
\text { - não relaciona blocos } \\
\text { semanticamente } \\
\text { próximos, apenas } \\
\text { alguns significados. }\end{array}$ & $\begin{array}{l}\text { - um verbete: } \\
\text { solução polissêmica; } \\
\text { - não separa classes } \\
\text { gramaticais: total; } \\
\text {-intercala acepçóes } \\
\text { de V e N; } \\
\text {-sem guidewords; } \\
\text { - não relaciona acepções } \\
\text { semanticamente } \\
\text { próximas (mesmo que } \\
\text { estejam em sequência). }\end{array}$ & $\begin{array}{l}\text { - dois verbetes: } \\
\text { solução homonímica; } \\
\text { - um para cada classe } \\
\text { gramatical: morfológica; } \\
\text { - não relaciona } \\
\text { significados } \\
\text { semanticamente } \\
\text { próximos (mas ver } \\
\text { acepção } 7 \text { do N.); }\end{array}$ & $\begin{array}{l}\text { - um verbete: } \\
\text { solução polissêmica; } \\
\text { - blocos por classe } \\
\text { gramatical: parcial; } \\
\text { - usa guidewords; } \\
\text { - não relaciona } \\
\text { significados } \\
\text { semanticamente } \\
\text { próximos. }\end{array}$ \\
\hline
\end{tabular}




\begin{tabular}{|c|c|c|c|c|}
\hline sack & $\begin{array}{l}\text { - um verbete: } \\
\text { solução polissêmica; } \\
\text { - blocos por classe } \\
\text { gramatical: parcial; } \\
\text { - guidewords, num } \\
\text { bloco único; } \\
\text { - não relaciona } \\
\text { significados } \\
\text { semanticamente } \\
\text { próximos a não ser } \\
\text { pela guideword. }\end{array}$ & 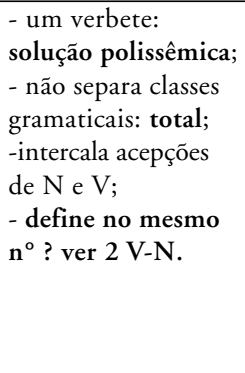 & $\begin{array}{l}\text { - dois verbetes: } \\
\text { solução homonímica; } \\
\text { - um para cada classe } \\
\text { gramatical: morfológica; } \\
\text { - sem guidewords; } \\
\text { - relaciona acepções } \\
\text { próximas (nº } 1 \text {, } \\
\text { hierárquica a e b = } \\
\text { metonímia); }\end{array}$ & $\begin{array}{l}\text { - um verbete: } \\
\text { solução polissêmica; } \\
\text { - blocos por classe } \\
\text { gramatical: parcial; } \\
\text { - sem guidewords; } \\
\text { - não relaciona } \\
\text { significados } \\
\text { semanticamente } \\
\text { próximos. }\end{array}$ \\
\hline \begin{tabular}{|l|} 
vest \\
\end{tabular} & $\begin{array}{l}\text { - um verbete: } \\
\text { solução polissêmica; } \\
\text { - blocos por classe } \\
\text { gramatical: parcial; } \\
\text { - não traz acepção } \\
\text { para o verbo; } \\
\text { - sem guidewords. }\end{array}$ & $\begin{array}{l}\text { - um verbete: } \\
\text { solução polissêmica; } \\
\text { - não separa classes } \\
\text { gramaticais: total; } \\
\text {-sem guidewords. }\end{array}$ & $\begin{array}{l}\text { - dois verbetes: } \\
\text { solução homonímica; } \\
\text { - um para cada classe } \\
\text { gramatical: morfológica; } \\
\text { - sem guidewords; }\end{array}$ & $\begin{array}{l}\text { - um verbete: } \\
\text { solução polissêmica; } \\
\text { - blocos por classe } \\
\text { gramatical: parcial; } \\
\text { - sem guidewords; }\end{array}$ \\
\hline
\end{tabular}

Recebido em 05/03/2013. Aprovado em 31/10/2013. 